\title{
On the developmental theory of ageing. I. Starvation resistance and longevity in Drosophila melanogaster in relation to pre-adult breeding conditions
}

\author{
B. J. ZWAAN, R. BIJLSMA \& R. F. HOEKSTRA* \\ Department of Genetics, University of Groningen, Kerklaan 30, 9751 NN Haren, and *Department of Genetics, \\ Agricultural University, Dreyenlaan 2, 6703 HA Wageningen, The Netherlands
}

The developmental theory of ageing predicts a positive correlation between developmental time and adult longevity. Experiments that vary larval density and food level have been carried out to test this prediction. The results show differences in viability, developmental time, starvation resistance and adult longevity. It is concluded that pre-adult developmental time is not a causal factor for the determination of adult longevity in Drosophila melanogaster. The observed variation in adult longevity is discussed in relation to viability selection and changed adult physiology.

Keywords: ageing, developmental time, Drosophila melanogaster, longevity, starvation.

\section{Introduction}

Current theories of ageing can be roughly divided into two groups: evolutionary and non-evolutionary theories. The main evolutionary theories are the mutation accumulation (Medawar, 1952) and the negative pleiotropy theory of ageing (Williams, 1957). Although quite distinct (Kirkland, 1989), these theories are all based on the fact that the chances of survival of an individual decrease with age even in the absence of ageing. This means that the probability of reproduction will decrease with age and, therefore, the intensity of natural selection (Williams, 1957). As a consequence, there will be a tendency for accumulation of beneficial mutations early in life and of deleterious mutations late in life. These deleterious mutations will become apparent only under conditions where mortality is low. According to evolutionary theories senescence evolved as a non-adaptive trait for which no direct selection in nature occurs (Kirkland, 1989).

The developmental theory is the major non-evolutionary theory of ageing (Lints, 1978, 1988). This theory links development to ageing. Muller (1963) has argued that development is a continuous process in which senescence forms the last stage and, consequently, spontaneous ageing is part of normal development and differentiation of an organism. The theory considers life-span as an epigenetically controlled trait, i.e. whose expression is linked to the regulation of gene function and differentiation. This may imply that development and ageing are directed by the same set of genes, i.e. development and longevity are genetically linked. Environmental interference in these particular aspects of development may then be reflected in the time of onset of ageing and/or variations in life-span. Experimental work with homeotherms (e.g. rats) and insects (e.g. Drosophila) seems to confirm the genetic relationship between development and longevity (for a review see Lints, 1978; Mayer \& Baker, 1985).

In this paper we report upon experiments on the effect of larval rearing conditions on adult life-span and starvation resistance. It has been shown that increasing larval density results in an increased adult lifespan (Miller \& Thomas, 1958; Lints \& Lints, 1969). The positive correlation found between developmental time and adult longevity (Lints \& Lints, 1969) is caused by the increase in developmental time with larval density (Bakker, 1961; Barker \& Podger, 1970). However, this relation is not necessarily a causal one. Because of the decrease in viability and adult body weight with increasing larval crowding (Bakker, 1961; Barker \& Podger, 1970; Prout \& McChesney, 1985), viability selection during the pre-adult stage and/or a change in adult physiology induced during the pre-adult stage might be involved. 
The purposes of this study are twofold: (1) to establish the effects of larval crowding on adult longevity, and (2) to determine whether the relation between preadult developmental time and adult longevity is a causal one or the result of viability selection and/or a change in adult physiology during the pre-adult stage.

\section{Materials and methods}

\section{Strain and culture conditions}

The Groningen 83 wild type strain was used in all experiments. This strain was founded with 403 females captured in a fruitmarket in Groningen (Holland) in 1983. The strain is considered to possess a large amount of genetic variation. The experiments were carried out between March and November 1989. For all experiments flies were reared at $25^{\circ} \mathrm{C}, 45$ per cent R.H. and at continuous light.

\section{Experiments}

In experiment 1 (Table 1) flies were reared in vials with $8 \mathrm{ml}$ of standard medium, which contained $32 \mathrm{~g}$ dead yeast, $54 \mathrm{~g}$ sugar, $17 \mathrm{~g}$ agar, $13 \mathrm{ml}$ nipagine solution (10 g nipagine in $100 \mathrm{ml} 96$ per cent ethanol; to avoid mould) and $250 \mathrm{mg}$ streptomycin (to avoid bacterial growth) per litre. Four egg-densities were used, ranging from 50 to 350 eggs per vial (indicated as D50 etc.; Table 1). It can be seen that with increasing density, the available amounts of yeast and sugar per egg decrease. Experiment 1 was carried out twice. The first time the

Table 1 Design of experiment 1 (larval crowding) and experiment 2 (food and density)

\begin{tabular}{lllll}
\hline \multirow{4}{*}{ Experiment } & \multicolumn{3}{c}{ Vial condition } \\
\cline { 3 - 5 } & Group & $\begin{array}{l}\text { Number } \\
\text { of eggs }\end{array}$ & $\begin{array}{l}\text { mg yeast/ } \\
\text { egg }\end{array}$ & $\begin{array}{l}\text { mg sugar/ } \\
\text { egg }\end{array}$ \\
\hline 1 & D50 & 50 & 5.12 & 8.64 \\
& D150 & 150 & 1.71 & 2.88 \\
& D250 & 250 & 1.02 & 1.73 \\
& D350 & 350 & 0.73 & 1.23 \\
& A3 & 50 & 0.73 & 1.23 \\
& A2 & 50 & 1.02 & 1.73 \\
& A1 & 50 & 1.71 & 2.88 \\
& AB & 50 & 5.12 & 8.64 \\
B1 & 150 & 5.12 & 2.88 \\
B2 & 250 & 5.12 & 1.73 \\
& B3 & 350 & 5.12 & 1.23 \\
& C & 50 & 5.12 & 8.64 \\
\hline
\end{tabular}

${ }^{*}$ Larvae allowed to feed for $60 \mathrm{~h}$ (see text). experiment was done to establish the effect of crowding (egg-density) on adult longevity and to measure developmental time and viability. Flies from this experiment were also used in a pilot experiment to develop methods for measuring starvation resistance. The second time the experiment was carried out to determine the effect of crowding on adult starvation resistance in relation to fat content using the methods developed in the pilot experiment.

In experiment 2 (Table 1) food effects (Part A, A3 to $\mathrm{AB}$ ) and density effects (part $\mathrm{B}, \mathrm{AB}$ to $\mathrm{B} 3$ ) of crowding were investigated. In part A egg-density was held constant, but the amounts of yeast/egg and sugar/egg were applied in such a way that food levels corresponded with the food levels in experiment 1 (Table 1 ). In part B the egg-density was increased as in experiment 1 , but the amount of yeast per egg was held constant (Table 1). This meant that extra yeast had to be added to the medium. The sugar level, however, could not be increased because the osmotic pressure of the medium would have become too high for normal larval development (David et al., 1983). As a result the amount of sugar per egg was the same as in experiment 1 (Table 1).

In experiment 2 there was an additional group of larvae (denoted $\mathrm{C}$ ), which were allowed to feed on standard food (set up with 50 eggs/vial) for a period of $60 \mathrm{~h}$ before they were transferred into groups of 25 to vials containing only agar. This larval feeding period is known to reduce adult body weight in both sexes by about 50 per cent, whereas more than 80 per cent of the transferred larvae will survive to adults (Bakker, 1961).

\section{Egg collecting}

To obtain eggs, 40 groups of about 30 pairs of flies were allowed to lay eggs on standard food. In experiment 1 a 15 -h and in experiment 2 an 8 -h laying period was used. After oviposition eggs were distributed over vials in the desired densities. At eclosion all flies were collected as virgins and throughout the experiments sexes were kept apart. The number of vials per group varied between 10 and 25 (Tables 3,5) to ensure enough experimental flies in each group.

\section{Developmental time}

Egg-to-adult developmental time was determined by counting the number of eclosed flies at regular intervals (twice a day), until all flies had emerged. Using regression of eclosing percentages (after probit transformation) on time (after logarithmic transformation) following the method devised by Finney (1947), 
median developmental time could be calculated. This calculation was done for each vial and the mean developmental time $(h)$ was calculated for each experimental group.

\section{Viability}

Viability (egg-to-adult survival) was measured as the ratio of the total number of emerged flies to initial egg density of vials. Mean viability could be calculated over vials in each experimental group. For statistical analysis, angular transformation was applied to viability data.

\section{Longevity}

Longevity was determined at $29^{\circ} \mathrm{C}$ in continuous light. For each experimental group, 25 females and 25 males were taken to measure mean longevity. This was done by scoring the vials for deceased individuals at regular intervals (three times a week). Longevity (in days) of an individual fly was taken as the midpoint between two successive scorings. In this way mean longevity could be calculated over all individuals for each group and sex. Vials, containing $5 \mathrm{ml}$ of standard food, were renewed for practical reasons only once a week. Escaped flies and accidental deaths were replaced throughout the experiment by reserve flies. In this way, the total number could be maintained at 25 individuals, except for the D50 and AB groups, where numbers fell below 25 because of a high number of accidental deaths (Tables 2 and 4). Because of detrimental effects of mating (Partridge, 1986; Service, 1989) and of higher adult densities (Boulétreau-Merle, 1988) on longevity, flies were housed singly and as virgins throughout the experiment.

\section{Starvation resistance}

Starvation resistance was measured as total survival time in vials containing only agar (for preventing desiccation) at $25^{\circ} \mathrm{C}$ in continuous light. Twice a day vials were scored for deceased individuals and survival time $(h)$ was taken as the midpoint between two successive scorings, similar to the longevity assays. For each experimental group and sex, starvation resistance was measured for 25 individuals. Flies were aged (in groups of 5) for about 28 days before starvation resistance was measured. This was done because starvation resistance (Service et al., 1985) and relative fat content (Fairbanks \& Burch, 1970, 1974) increase with age for female $D$. melanogaster until a plateau value is reached for both characters at about 21 days of age. During the starvation test the flies were housed singly and as
Table 2 Means and standard deviations (in parentheses) of adult longevity ( $n$, number of adults) pre-adult developmental time ( $n$, number of vials) and adult body weight $(n$, number of replicates) in experiment 1

\begin{tabular}{llll}
\hline Group & $\begin{array}{l}\text { Longevity } \\
\text { (days) }\end{array}$ & $\begin{array}{l}\text { Developmental } \\
\text { time }(\mathrm{h})\end{array}$ & $\begin{array}{l}\text { Body weight } \\
(\mathrm{mg})\end{array}$ \\
\hline Females & & & \\
D50 & $37.9(6.3)$ & $233.2(6.7)$ & $1.402(0.045)$ \\
$n$ & 9 & 20 & 5 \\
D150 & $39.2(8.0)$ & $260.8(3.1)$ & $1.262(0.052)$ \\
$n$ & 25 & 15 & 12 \\
D250 & $43.9(7.8)$ & $307.1(7.4)$ & $1.128(0.066)$ \\
$n$ & 25 & 10 & 15 \\
D350 & $49.6(11.0)$ & $353.4(10.1)$ & $1.024(0.056)$ \\
$n$ & 25 & 10 & 11 \\
Males & & & \\
D50 & $32.4(10.9)$ & $241.2(3.1)$ & $0.942(0.036)$ \\
$n$ & 14 & 20 & 5 \\
D150 & $33.7(10.9)$ & $258.5(6.9)$ & $0.769(0.039)$ \\
$n$ & 25 & 15 & 15 \\
D250 & $37.2(9.5)$ & $302.6(5.3)$ & $0.684(0.045)$ \\
$n$ & 25 & 10 & 14 \\
D350 & $43.2(8.9)$ & $357.0(16.7)$ & $0.642(0.035)$ \\
$n$ & 25 & 10 & 14 \\
\hline
\end{tabular}

virgins because of detrimental effects of mating on starvation resistance (Service 1989).

Two additional measurements on starvation resistance were carried out in experiment one. (1) Apart from measurements at age 28 days (age group 2), we measured the survival at about 15 days of age (age group 1), to see if differences occurred between the density groups on reaching the plateau value of starvation resistance. Twenty-five individuals of each sex were used, except for group D350 (age group 1), where only 19 individuals could be taken. (2) Because of the positive correlation between time to eclosing and crowding, starvation resistance at higher densities ( $>150$ eggs) was measured for flies which had eclosed when 25,50 or 75 per cent of the total number of flies had emerged.

\section{Relative fat content}

When a starvation resistance experiment was started, flies from each group were taken to determine the fat content. The relative amount of fat is a determinant parameter for survival time without food (David et al., 1975a,b; Service 1987). Samples were weighed and dried (killed) at $70^{\circ} \mathrm{C}$ for about $48 \mathrm{~h}$ and weighed again to obtain dry weights. The fat weight of these flies was measured using ether-extraction over a 24-h period (Fairbanks \& Burch, 1970; David et al., 1975a,b). The 
difference in weight before (dry weight) and after (fatfree dry weight) extraction is the adult fat weight. The relative fat content was given as the ratio of fat weight to wet body weight. Each sample consisted of five flies and for each group, five replicates were taken, except for some groups in experiment 1 where only two to four replicates could be taken (Table 6 ). In one case (age group 1, D350; Table 6) no flies at all could be obtained for fat assays, because of the shortage of flies. All weights were measured to the nearest $0.001 \mathrm{mg}$. Angular transformation was applied to the relative fat content data for statistical analysis.

\section{Data analysis}

To ascertain whether larval density and/or food level variation had significant effects on the above mentioned parameters, analyses of variance (one and two-way ANOVA) were carried out. Differences between experimental groups were tested for significance using the Student-Newman-Keuls procedure (SNK-test, corrected for unequal sample sizes; Sokal \& Rohlf, 1969).

\section{Results}

Adult longevity (Table 2) increased significantly with increasing larval crowding for both females and males (respectively: $F_{3.83}=7.09, P<0.001$ and $F_{3.88}=5.08$, $P<0.01 ; \quad$ SNK-test, $\quad \mathrm{D} 50=\mathrm{D} 150=\mathrm{D} 250<\mathrm{D} 350)$. Moreover, as commonly found for crowding, it also significantly affected developmental time, adult body weight and viability. Developmental time was increased for both females and males (Table 2; respectively: $F_{3,54}=771.8, P<0.001$ and $F_{3,54}=477.4, P<0.001$; SNK-test, D50 $<$ D $150<\mathrm{D} 250<\mathrm{D} 350$ ). Adult body weight decreased for females and for males with increasing crowding levels (Table 2; respectively: $F_{3,42}=56.8, P<0.001$ and $F_{3,47}=87.7, P<0.001$; SNK-test, D50 $>$ D150 $>$ D250 $>$ D350). Viability decreased significantly with increased crowding (Table $3 ; F_{3,52}=97.9, P<0.001 ;$ SNK-test, D50 $>$ D $150>$ $\mathrm{D} 250=\mathrm{D} 350$ ).

Table 3 Mean viability and standard deviations (in parentheses) in experiment 1 ( $n$, number of vials)

\begin{tabular}{lll}
\hline Group & $n$ & Viability \\
\hline D50 & 20 & $0.906(0.057)$ \\
D150 & 15 & $0.694(0.059)$ \\
D250 & 10 & $0.624(0.022)$ \\
D350 & 10 & $0.592(0.042)$ \\
\hline
\end{tabular}

In part $\mathrm{A}$ of the second experiment, developmental time significantly increased with a decrease in food level (Table 4; females $F_{3,84}=1380.1, P<0.001$; males $F_{3,84}=1276.3, \quad P<0.001 ; \quad$ SNK-test,$\quad \mathrm{AB}<\mathrm{A} 1<$ $\mathrm{A} 2<\mathrm{A} 3$ ). Adult body weight also decreased with decreasing food levels for both sexes (females, $F_{3,19}=$ 56.1, $P<0.001$; SNK-test, $\mathrm{AB}>\mathrm{A} 1>\mathrm{A} 2>\mathrm{A} 3$; males, $F_{3,19}=16.0, P<0.001 ;$ SNK-test, $\mathrm{A} 1=\mathrm{AB}=\mathrm{A} 2>\mathrm{A} 3$ ). These effects were approximately the same as those observed for larval crowding in experiment 1. Similar results were found by Economos \& Lints (1984a). However, viability and adult longevity were affected differently compared to larval crowding. Although

Table 4 Means and standard deviations (in parentheses) of adult longevity ( $n$, number of adults) pre-adult developmental time ( $n$, number of vials) and adult body weight ( $n$, number of replicates) in experiment 2

\begin{tabular}{|c|c|c|c|}
\hline Group & $\begin{array}{l}\text { Longevity } \\
\text { (days) }\end{array}$ & $\begin{array}{l}\text { Developmental } \\
\text { time }(\mathrm{h})\end{array}$ & $\begin{array}{l}\text { Body weight } \\
(\mathrm{mg})\end{array}$ \\
\hline \multicolumn{4}{|c|}{ Females } \\
\hline A3 & $25.6(8.3)$ & $359.0(11.7)$ & $1.089(0.045)$ \\
\hline$n$ & 25 & 25 & 5 \\
\hline $\mathrm{A} 2$ & $20.8(7.9)$ & $315.1(8.3)$ & $1.218(0.067)$ \\
\hline$n$ & 25 & 20 & 5 \\
\hline A1 & $27.1(7.6)$ & $271.2(4.3)$ & $1.357(0.042)$ \\
\hline$n$ & 25 & 15 & 5 \\
\hline $\mathrm{AB}$ & $28.5(7.7)$ & $216.1(4.6)$ & $1.479(0.044)$ \\
\hline$n$ & 17 & 25 & 5 \\
\hline B1 & $28.9(7.7)$ & $199.1(1.8)$ & $1.478(0.091)$ \\
\hline$n$ & 25 & 15 & 5 \\
\hline $\mathrm{B} 2$ & $33.0(11.1)$ & $200.0(3.0)$ & $1.320(0.061)$ \\
\hline$n$ & 25 & 15 & 5 \\
\hline B3 & $36.3(8.0)$ & $205.0(3.3)$ & $1.380(0.056)$ \\
\hline$n$ & 25 & 15 & 5 \\
\hline $\mathrm{C}$ & $32.7(10.7)$ & $210.6(3.8)$ & $0.678(0.070)$ \\
\hline$n$ & 25 & 20 & 5 \\
\hline \multicolumn{4}{|l|}{ Males } \\
\hline A3 & $26.3(8.4)$ & $358.1(12.2)$ & $0.726(0.048)$ \\
\hline$n$ & 25 & 25 & 5 \\
\hline $\mathrm{A} 2$ & $24.7(9.9)$ & $315.4(7.7)$ & $0.831(0.029)$ \\
\hline$n$ & 25 & 20 & 5 \\
\hline A1 & $24.2(11.2)$ & $272.1(2.5)$ & $0.873(0.043)$ \\
\hline$n$ & 25 & 15 & 5 \\
\hline$A B$ & $23.6(7.8)$ & $221.3(4.7)$ & $0.859(0.024)$ \\
\hline$n$ & 25 & 25 & 5 \\
\hline B1 & $23.4(8.5)$ & $204.2(2.1)$ & $0.836(0.020)$ \\
\hline$n$ & 25 & 15 & 5 \\
\hline $\mathrm{B} 2$ & $35.3(12.0)$ & $209.8(1.7)$ & $0.813(0.010)$ \\
\hline$n$ & 25 & 15 & 5 \\
\hline B3 & $36.7(11.0)$ & $212.9(2.0)$ & $0.821(0.024)$ \\
\hline$n$ & 25 & 15 & 5 \\
\hline $\mathrm{C}$ & $35.8(10.2)$ & $217.7(4.2)$ & $0.456(0.016)$ \\
\hline$n$ & 25 & 20 & 5 \\
\hline
\end{tabular}


there was a decrease in viability with decreasing food levels (Table $5 ; F_{3,83}=4.95, P<0.01$ ), only group A3 differed significantly from group $A B$ (SNK-test). This reduction in viability, however, was considerably less severe than for larval crowding (Table 3). For females adult longevity was significantly affected by decreasing food levels (Table $4 ; F_{3,91}=4.05, P<0.01$ ), however, female longevity was not increased as for larval crowding in experiment 1 . On the whole female longevity was slightly reduced as compared to the control (SNK-test, $\mathrm{AB}=\mathrm{A} 1=\mathrm{A} 3>\mathrm{A} 2)$. Male longevity was increased by about 2.5 days with decreasing food levels (Table 4) but this effect was not statistically significant $\left(F_{3,99}=0.38, P<0.80\right)$. In general, female and male longevities were not seriously altered by decreasing food levels.

Where the yeast level was kept constant (exp. 2, part B), significant effects on developmental time were observed (Table 4; females $F_{3,69}=101.3, P<0.001$; males $\left.F_{3,69}=98.2, P<0.001\right)$. For both sexes developmental times of groups B1 to B3 were significantly shorter as compared to group $\mathrm{AB}$ (SNK-test). This effect was probably due to the smoother constitution of the food because of the higher yeast levels relative to the amount of agar, which made the food more accessible to developing larvae. However, for group B1 to B3, developmental time was slightly, nevertheless significantly, increased with increasing larval density (SNK-test, females $\mathrm{B} 1=\mathrm{B} 2<\mathrm{B} 3$ and males $\mathrm{B} 1<\mathrm{B} 2<\mathrm{B} 3)$. For both sexes, groups B2-B3 had a significantly reduced body weight as compared to groups $\mathrm{AB}-\mathrm{B} 1$ even though the amount of yeast/egg was held constant (Table 4; females $F_{3,19}=7.05$, $P<0.01$; males $F_{3,19}=5.03, P<0.025$; SNK-test $)$. However, this reduction in body size was only about 11 per cent for females and about 5 per cent for males, as compared to about a 30 per cent reduction in body size for both sexes in the larval crowding experiment

Table 5 Mean viability and standard deviation (in parentheses) in experiment 2 ( $n$, number of vials)

\begin{tabular}{lll}
\hline Group & $n$ & Viability \\
\hline A3 & 25 & $0.734(0.063)$ \\
A2 & 20 & $0.768(0.071)$ \\
A1 & 15 & $0.781(0.053)$ \\
AB & 25 & $0.815(0.081)$ \\
B1 & 15 & $0.766(0.044)$ \\
B2 & 15 & $0.696(0.079)$ \\
B3 & 15 & $0.718(0.046)$ \\
C & 20 & $0.816(0.110)^{*}$ \\
\hline
\end{tabular}

${ }^{*}$ Larval-to-adult survival (see text).
(Table 2). Apparently, by keeping yeast/egg levels constant, the effects of larval crowding on developmental time could be overcome, whereas some residual effect of crowding on body size remained (see also Economos \& Lints, 1984a). Viability was reduced at higher larval densities but again less severely than for the larval crowding experiment (Table 5; $F_{3,68}=11.0$, $P<0.001 ; \quad$ SNK-test, $\quad \mathrm{AB}>\mathrm{B} 1=\mathrm{B} 3=\mathrm{B} 2 \quad$ and $\mathrm{B} 1>\mathrm{B} 2)$.

Interestingly, even when the amount of yeast/egg was kept constant, increasing larval density was accompanied by an increase in longevity (Table 4; females $F_{3,91}=3.97, P<0.025$; SNK-test, group B3 significantly differed from $\mathrm{AB}$ and $\mathrm{B} 1$, and males $F_{3,99}=13.3, P<0.001$; SNK-test, $\mathrm{AB}=\mathrm{B} 1<\mathrm{B} 2=\mathrm{B} 3$ ). There appeared to be a clear distinction in longevity between density groups 50-150 and 250-350, because the latter group showed a 6-day higher longevity in females and an 11-day higher longevity in males as compared to the former group.

Adults from group $\mathrm{C}$ showed about half the body size of the control group (Table 4; females $t_{8}=21.6$, $P<0.001$; males $\left.t_{8}=30.9, P<0.001\right)$. Similar results were found by Bakker (1961). The developmental time (Table 4) was somewhat reduced (about $6 \mathrm{~h}$ ) for both sexes (females $t_{43}=4.27, P<0.001$; males $t_{43}=2.72$, $P<0.01)$. This effect probably resulted from the lower larval density in group $\mathrm{C}$ as compared to group $\mathrm{AB}$. The survival of larvae transferred after $60 \mathrm{~h}$ did not differ greatly from the viability of eggs in the control group (AB; $t_{39}=0.98, P<0.40$ ). As about 20 per cent of the young larvae die during the first $60 \mathrm{~h}$ of development, the actual egg-to-adult survival of group $\mathrm{C}$ must have been considerably lower. Assuming that almost all mortality occurs during these first $60 \mathrm{~h}$, the actual eggto-adult survival in group $\mathrm{C}$ was estimated by viability group $\mathrm{AB} \times$ viability group $\mathrm{C}$ is $0.815 \times 0.816=0.67$.

The longevity of group $\mathrm{C}$ adults of both sexes was increased compared to the control (Table 4), this effect was significant for males $\left(t_{48}=4.76, P<0.001\right)$ but not for females $\left(t_{40}=1.39, P<0.20\right)$.

Starvation resistance (Table 6 ) of female and male flies increased with increasing larval crowding for age groups 1 and 2 (age group 1 , females $F_{3,93}=15.1$, $P<0.001 ; \quad$ SNK-test, $\quad$ D $50<\mathrm{D} 150=\mathrm{D} 250=\mathrm{D} 350$ and $\mathrm{D} 150<\mathrm{D} 350$, and males $F_{3,93}=88.8, P<0.001$; SNK-test, $\mathrm{D} 150=\mathrm{D} 50<\mathrm{D} 250=\mathrm{D} 350 ;$ age group 2 , females $F_{3,249}=8.67, \quad P<0.001 ; \quad$ SNK-test, $\mathrm{D} 50=\mathrm{D} 150<\mathrm{D} 250=\mathrm{D} 350$, and males $F_{3,249}=38.8$, $P<0.001$; SNK-test, D50 $<\mathrm{D} 150<\mathrm{D} 250<\mathrm{D} 350$ ). The 'time of eclosing' had a significant effect on starvation resistance of females (Table 6, age group 2; $\left.F_{2,249}=8.16, P<0.001\right)$ : later females survived longer than early emerging females. There was no suggestion 
Table 6 Means and standard deviations (in parentheses) of starvation resistance (SR, $\mathrm{h} ; n$, number of adults) and relative fat content (FC, fat $/ \mathrm{mg}$ wet weight; $n$, number of replicates) in experiment 1 for the two age groups and different 'times of eclosing' (when 25,50 or 75 per cent of the total number of flies had emerged)

\begin{tabular}{|c|c|c|c|c|c|c|c|c|}
\hline \multirow[b]{3}{*}{ Group } & \multirow{2}{*}{\multicolumn{2}{|c|}{$\frac{\text { Age group } 1}{50 \%}$}} & \multicolumn{6}{|c|}{ Age group 2} \\
\hline & & & \multicolumn{2}{|l|}{$25 \%$} & \multicolumn{2}{|l|}{$50 \%$} & \multicolumn{2}{|l|}{$75 \%$} \\
\hline & SR & $\mathrm{FC}$ & SR & $\mathrm{FC}$ & SR & FC & SR & $\mathrm{FC}$ \\
\hline \multicolumn{9}{|l|}{ Females } \\
\hline D50 & $\begin{array}{c}125.0 \\
(34.7)\end{array}$ & $\begin{array}{c}0.160 \\
(0.012)\end{array}$ & - & - & $\begin{array}{l}154.6 \\
(50.3)\end{array}$ & $\begin{array}{c}0.161 \\
(0.013)\end{array}$ & - & - \\
\hline$n$ & 25 & 5 & & & 25 & 5 & & \\
\hline D150 & $\begin{array}{l}170.0 \\
(46.3)\end{array}$ & $\begin{array}{c}0.186 \\
(0.024)\end{array}$ & $\begin{array}{l}148.8 \\
(42.0)\end{array}$ & $\begin{array}{c}0.164 \\
(0.016)\end{array}$ & $\begin{array}{l}167.3 \\
(47.0)\end{array}$ & $\begin{array}{c}0.194 \\
(0.020)\end{array}$ & $\begin{array}{l}175.0 \\
(47.5)\end{array}$ & $\begin{array}{c}0.175 \\
(0.032)\end{array}$ \\
\hline$n$ & 25 & 5 & 25 & 5 & 25 & 5 & 25 & 2 \\
\hline D250 & $\begin{array}{l}191.9 \\
(37.4)\end{array}$ & $\begin{array}{c}0.206 \\
(0.011)\end{array}$ & $\begin{array}{l}160.1 \\
(33.0)\end{array}$ & $\begin{array}{c}0.209 \\
(0.062)\end{array}$ & $\begin{array}{l}205.7 \\
(53.7)\end{array}$ & $\begin{array}{c}0.239 \\
(0.016)\end{array}$ & $\begin{array}{l}221.8 \\
(60.1)\end{array}$ & $\begin{array}{c}0.230 \\
(0.021)\end{array}$ \\
\hline$n$ & 25 & 5 & 25 & 5 & 25 & 5 & 25 & 5 \\
\hline D350 & $\begin{array}{l}204.6 \\
(55.7)\end{array}$ & - & $\begin{array}{c}197.5 \\
(74.3)\end{array}$ & $\begin{array}{c}0.212 \\
(0.028)\end{array}$ & $\begin{array}{l}205.8 \\
(78.4)\end{array}$ & $\begin{array}{c}0.196 \\
(0.028)\end{array}$ & $\begin{array}{l}214.9 \\
(40.7)\end{array}$ & $\begin{array}{c}0.178 \\
(0.071)\end{array}$ \\
\hline$n$ & 19 & & 25 & 4 & 25 & 5 & 25 & 2 \\
\hline \multicolumn{9}{|l|}{ Males } \\
\hline D50 & $\begin{array}{c}47.2 \\
(11.0)\end{array}$ & $\begin{array}{l}0.045 \\
(0.012)\end{array}$ & - & - & $\begin{array}{c}45.8 \\
(12.6)\end{array}$ & $\begin{array}{c}0.069 \\
(0.008)\end{array}$ & - & - \\
\hline$n$ & 25 & 5 & & & 25 & 5 & & \\
\hline D150 & $\begin{array}{c}42.4 \\
(12.5)\end{array}$ & $\begin{array}{c}0.117 \\
(0.015)\end{array}$ & $\begin{array}{c}55.1 \\
(12.9)\end{array}$ & $\begin{array}{c}0.082 \\
(0.009)\end{array}$ & $\begin{array}{c}68.2 \\
(28.5)\end{array}$ & $\begin{array}{c}0.107 \\
(0.023)\end{array}$ & $\begin{array}{c}69.3 \\
(27.3)\end{array}$ & $\begin{array}{c}0.108 \\
(0.022)\end{array}$ \\
\hline$n$ & 25 & 5 & 25 & 5 & 25 & 5 & 25 & 5 \\
\hline D250 & $\begin{array}{l}137.8 \\
(42.4)\end{array}$ & $\begin{array}{c}0.166 \\
(0.022)\end{array}$ & $\begin{array}{c}99.4 \\
(34.8)\end{array}$ & $\begin{array}{c}0.155 \\
(0.019)\end{array}$ & $\begin{array}{l}124.2 \\
(57.3)\end{array}$ & $\begin{array}{c}0.187 \\
(0.039)\end{array}$ & $\begin{array}{c}79.7 \\
(29.8)\end{array}$ & $\begin{array}{c}0.158 \\
(0.010)\end{array}$ \\
\hline$n$ & 25 & 5 & 25 & 5 & 25 & 5 & 25 & 4 \\
\hline D350 & $\begin{array}{l}141.8 \\
(34.4)\end{array}$ & - & $\begin{array}{l}127.8 \\
(59.4)\end{array}$ & $\begin{array}{c}0.177 \\
(0.030)\end{array}$ & $\begin{array}{l}120.5 \\
(42.4)\end{array}$ & $\begin{array}{c}0.164 \\
(0.049)\end{array}$ & $\begin{array}{l}121.5 \\
(51.1)\end{array}$ & $\begin{array}{c}0.160 \\
(0.016)\end{array}$ \\
\hline$n$ & 19 & & 25 & 5 & 25 & 4 & 25 & 5 \\
\hline
\end{tabular}

of an interaction between larval density and the 'time of eclosing' $\left(F_{4,249}=1.33, P<0.30\right)$, which implied that the effects of larval crowding on starvation resistance remained the same for all emerging groups. For males the 'time of eclosing' had no consistent effect on starvation resistance $\left(F_{2,249}=2.63, P<0.10\right)$. Comparing the age groups revealed that no differences exist in reaching the plateau value in starvation resistance (Service $e t$ al., 1985) for the different larval densities. Most density groups had already reached the plateau value in age group 1. For all groups female flies had a much greater starvation resistance than males.

Table 6 also shows the relative fat content (fat $/ \mathrm{mg}$ wet weight) for adults at the beginning of each starvation experiment. For both age groups and sexes, the fat content of adults increased with increasing crowding (age group 1, females $F_{2,14}=9.62, P<0.01$; SNK-test, $\mathrm{D} 50<\mathrm{D} 150=\mathrm{D} 250$, males $F_{2,14}=74.3, \quad P<0.001$;
SNK-test, D50 $<$ D150 $<$ D250; age group 2, females $F_{3,42}=5.77, \quad P<0.01 ; \quad$ SNK-test, $\quad$ D $50=\mathrm{D} 150=$ D350<D250, males $F_{3,47}=40.1, P<0.001$; SNK-test, $\mathrm{D} 50<\mathrm{D} 150<\mathrm{D} 250=\mathrm{D} 350)$. It is important to note that a significant positive correlation between starvation resistance and relative fat content was observed $(r=0.89, P<0.001$; Table 6, Fig. 1$)$, which means that the fat content at the beginning of the starvation period determines to a large extent the total survival time without food (David et al., 1975a,b, 1983). In this way differences between the sexes in starvation resistance could be explained by the differences in fat content between the sexes (Table 6, Fig. 1).

Reduction of food levels (exp. 2, part A) resulted in a significant increase in starvation resistance (Table 7) for males $\left(F_{3,99}=12.3, P<0.001\right.$; SNK-test, $\mathrm{AB}<\mathrm{A} 1$ $\mathrm{A} 3$ and $\mathrm{A} 3>\mathrm{AB}-\mathrm{A} 2)$, but had no significant effect on female starvation resistance $\left(F_{3,99}=0.43, P<0.80\right)$. 


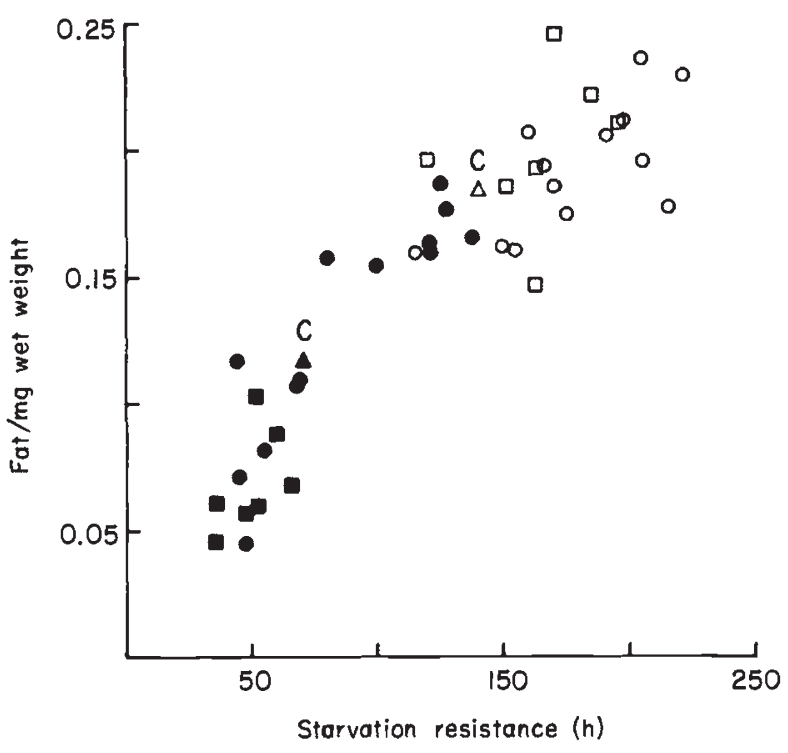

Fig. 1 The relation between starvation resistance and relative fat content for all data of experiments 1 and 2. (0) 우우

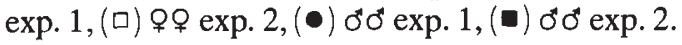

The fat content in this part of experiment 2 was significantly affected in both sexes by a decreased food level (Table 7 ; females $F_{3,19}=7.37, \quad P<0.01 ;$ males $\left.F_{3,19}=5.36, P<0.01\right)$. For females group A3 had a significantly higher fat content than groups $\mathrm{AB}$ to $\mathrm{A} 2$ (SNK-test), while for males group $\mathrm{AB}$ had a significantly lower fat content than groups A1 to A3 (SNKtest).

Where yeast/egg levels were kept constant (exp. 2, part B) starvation resistance in males was increased with increasing larval density (Table $7, F_{3.99}=11.7$, $P<0.001$; SNK-test, $\mathrm{AB}=\mathrm{B} 1<\mathrm{B} 3=\mathrm{B} 2$ ). Also for females starvation resistance was significantly affected by larval density $\left(F_{3,99}=7.86, P<0.001\right)$. Females of group B1 had an exceptionally low survival time (SNKtest, $\mathrm{B} 1<\mathrm{AB}=\mathrm{B} 2=\mathrm{B} 3$ ), but, in general, the resistance in high density groups (B2-B3) was greater than in low density groups. The fat content increased with increasing larval density for both sexes (Table 7) and was significant for males $\left(F_{3,19}=17.7, P<0.001\right.$; SNK-test, $\mathrm{AB}=\mathrm{B} 1<\mathrm{B} 2=\mathrm{B} 3)$ but not for females $\left(F_{3,19}=0.97\right.$, $P<0.50)$.

As in experiment 1 , females showed a greater starvation resistance than males in both parts of experiment 2 (Table 7). Again starvation resistance and relative fat content were positively correlated $(r=0.93$, $P<0.001$; Table 7, Fig. 1) and differences between the sexes in starvation resistance were reasonably well explained by differences in fat content (Fig. 1).

In males, adults of group $\mathrm{C}$ had a significantly higher starvation resistance $\left(t_{48}=4.60, P<0.001\right)$ and fat content $\left(t_{8}=10.6, P<0.001\right)$ compared to the control
Table 7 Means and standard deviations (in parentheses) of starvation resistance ( $n$, number of adults) and relative fat content $(n$, number of replicates) in experiment 2

\begin{tabular}{|c|c|c|}
\hline Group & $\mathrm{SR}(\mathrm{h})$ & $\begin{array}{l}\mathrm{FC} \text { (fat/ } \\
\text { mg wet wt) }\end{array}$ \\
\hline \multicolumn{3}{|c|}{ Females } \\
\hline A3 & $171.2(58.1)$ & $0.246(0.028)$ \\
\hline$n$ & 25 & 5 \\
\hline $\mathrm{A} 2$ & $151.6(73.2)$ & $0.186(0.029)$ \\
\hline$n$ & 25 & 5 \\
\hline A1 & $163.4(66.5)$ & $0.147(0.032)$ \\
\hline$n$ & 25 & 5 \\
\hline $\mathrm{AB}$ & $163.9(46.7)$ & $0.193(0.041)$ \\
\hline$n$ & 25 & 5 \\
\hline B1 & $119.6(49.7)$ & $0.196(0.035)$ \\
\hline$n$ & 25 & 5 \\
\hline $\mathrm{B} 2$ & $184.9(76.8)$ & $0.222(0.024)$ \\
\hline$n$ & 25 & 5 \\
\hline B3 & $196.4(63.4)$ & $0.211(0.016)$ \\
\hline$n$ & 25 & 5 \\
\hline $\mathrm{C}$ & $139.8(47.5)$ & $0.184(0.072)$ \\
\hline$n$ & 25 & 5 \\
\hline \multicolumn{3}{|l|}{ Males } \\
\hline A3 & $66.7(27.9)$ & $0.068(0.014)$ \\
\hline$n$ & 25 & 5 \\
\hline $\mathrm{A} 2$ & $47.7(14.2)$ & $0.057(0.008)$ \\
\hline$n$ & 25 & 5 \\
\hline A1 & $52.5(14.1)$ & $0.060(0.006)$ \\
\hline$n$ & 25 & 5 \\
\hline $\mathrm{AB}$ & $35.2(13.9)$ & $0.046(0.005)$ \\
\hline$n$ & 25 & 5 \\
\hline B1 & $35.7(15.1)$ & $0.061(0.008)$ \\
\hline$n$ & 25 & 5 \\
\hline $\mathrm{B} 2$ & $59.8(19.9)$ & $0.088(0.026)$ \\
\hline$n$ & 25 & 5 \\
\hline B3 & $52.1(21.7)$ & $0.103(0.010)$ \\
\hline$n$ & 25 & 5 \\
\hline $\mathrm{C}$ & $71.1(36.5)$ & $0.117(0.016)$ \\
\hline$n$ & 25 & 5 \\
\hline
\end{tabular}

(Table 7). Although female starvation resistance of group $\mathrm{C}$ adults was somewhat lower than the control flies (Table 7), no significant differences between these groups existed with respect to starvation resistance $\left(t_{48}=1.81, \quad P<0.10\right)$ and fat content $\left(t_{8}=0.35\right.$, $P<0.80)$. The observed data for group $\mathrm{C}$ males and females fit reasonably well into the perceived relationship between starvation resistance and fat content (Fig. 1). Apparently, different developmental conditions do not change the physiological dependence of starvation resistance on the relative fat content.

From these results it becomes apparent that there was no unequivocal relationship between pre-adult developmental time and adult longevity (Fig. 2). 


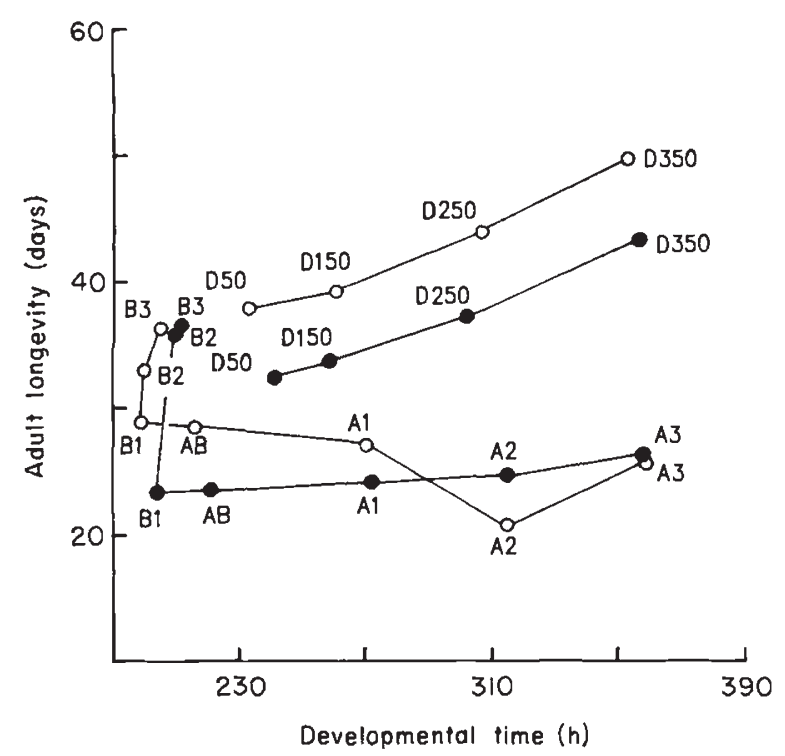

Fig. 2 The relation between developmental time and adult longevity using the data for both sexes and experiments.

(০) Female, (•) male.

Although for the larval crowding experiment (exp. 1) a positive correlation existed between developmental time and longevity (Table 2, Fig. 2), no such correlation was found in the second experiment (Table 4, Fig. 2). On the one hand, in part $\mathrm{A}$ when developmental time was increased, adult longevity was not seriously altered while in part B developmental time was virtually unchanged but adult longevity was increased.

Figure 3 shows that the data revealed a distinct negative correlation between viability and adult longevity $(r=-0.59, P<0.01$; Fig. 3$)$. Data points of group D50 deviated strongly from this correlation (Fig. 3), however, it should be stressed that this group had an exceptionally high viability (compare group $\mathrm{AB}$, Table 5).

A positive correlation was found between starvation resistance and adult longevity (females $r=0.60$, $P<0.05$; males $r=0.77, P<0.01$; Fig. 4) when all experiments were combined: greater adult longevity was accompanied by greater starvation resistance. Although females showed a greater starvation resistance than males, the slope of regression lines is more or less the same for both sexes, indicating a similar underlying relationship in both males and females.

\section{Discussion}

Both Miller \& Thomas (1958) and Lints \& Lints (1969) have shown that larval crowding increases adult longevity. This observation was long taken as support for the developmental theory of ageing because of the negative correlation between life-span and develop-

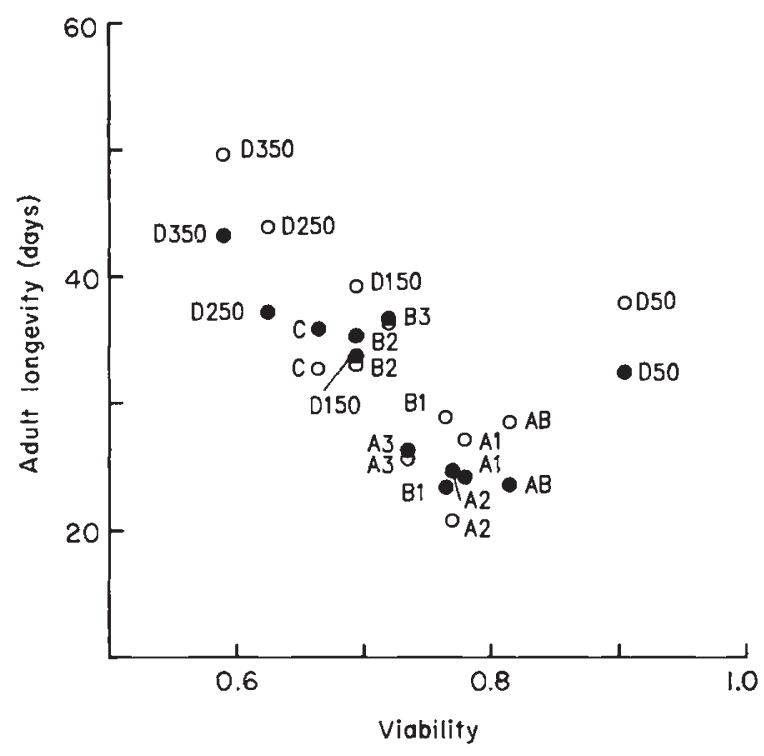

Fig. 3 The relation between viability (egg-to-adult survival) and adult longevity using the data for both sexes and experiments. (O) Female, (•) male.

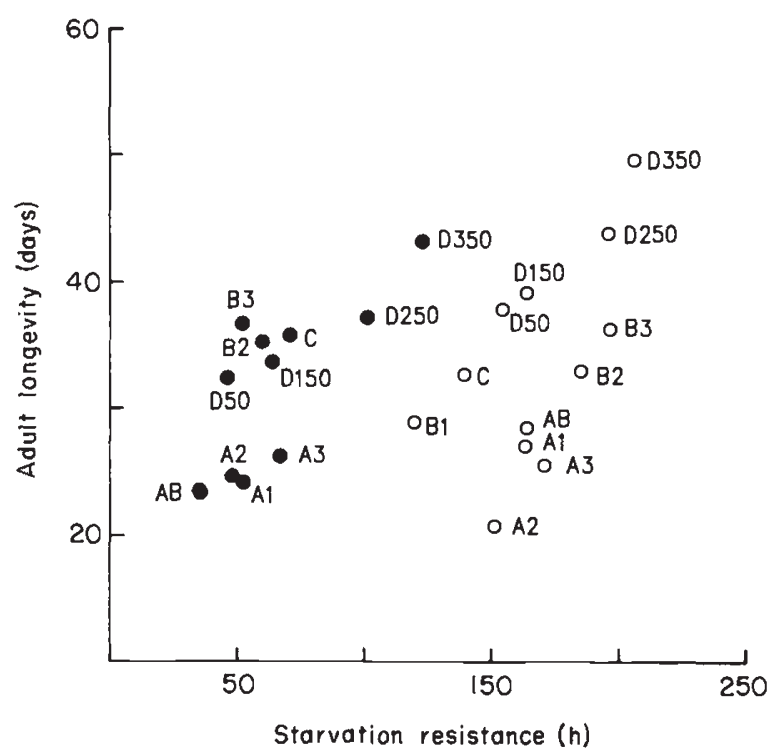

Fig. 4 The relation between starvation resistance and adult longevity using the data for both sexes and experiments. For the starvation resistance of density groups of experiment 1 the mean survival time of age group 2 is taken (Table 6).

(०) Female, (•) male.

mental rate (Lints \& Lints, 1971a,b; Lints, 1978, 1985). However, Economos \& Lints (1984b) showed that adult longevity in fact depended in a biphasic (parabolic) way on growth rate, and that duration of development was not a causative factor of life-span. This parabolic relationship between growth rate and life-span was found both through the manipulation of 
added yeast and larval crowding. However, when the growth rate is calculated from our data, using the same methods as Economos \& Lints (1984a,b), no consistent relation at all was found between adult longevity and growth rate for either experiment (Fig. 5). David and co-workers (1971) also did not observe such a relation: dilution of food resulted in a large increase in developmental time, and consequently a decrease in growth rate, but had no clear effect on adult longevity. This latter finding is in good agreement with our results of food level reduction (Table 4).

This clear-cut difference in results on growth rate and life-span might be explained by the experimental design used by Economos \& Lints (1984b). Variation in growth rate was obtained by varying yeast amounts added on top of the medium (Economos \& Lints, 1984a), whereas in our experiments all the yeast was mixed through the medium. This might cause some significant differences between the results because other parameters, e.g. viability and developmental time, are affected differently in the two experimental designs. However, from their experiments on the relation between developmental temperature and life-span Economos \& Lints (1986) also concluded that growth rate per se does not determine adult longevity.

It can be concluded, therefore, from both our and previous results, that developmental time and growth rate are not related to ageing in $D$. melanogaster. If developmental time and growth rate are not causally related to longevity, what can explain the observed variation in life-span in our experiments? At least two explanations seem appropriate.

1 If viability is decreased, only the fittest individuals survive to adults (viability selection) and this increase

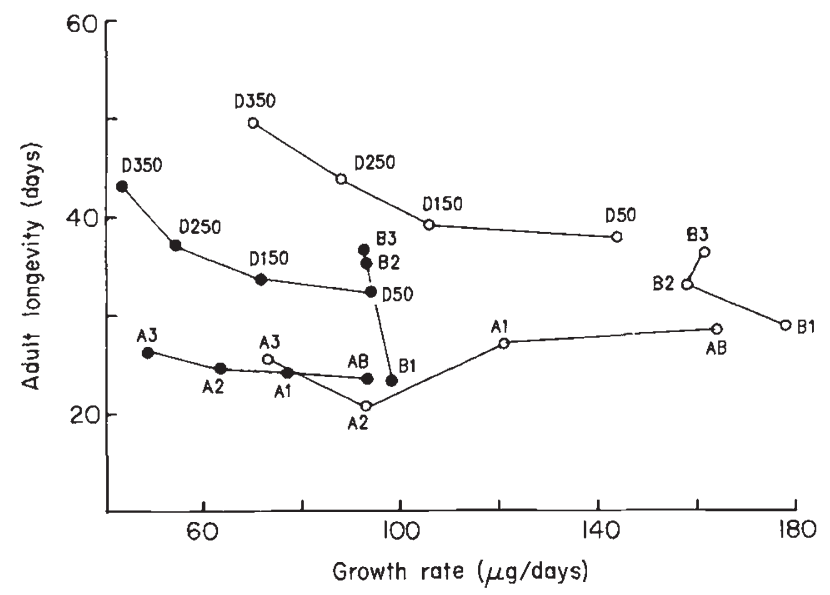

Fig. 5 The relation between growth rate and adult longevity using the data for both sexes and experiments. Growth rate is defined as the ratio of mean adult body weight to mean developmental time (Economos \& Lints, 1984b). (O) Female, (•) male. in mean fitness becomes evident in increased adult longevity and starvation resistance (fat content). In this case starvation resistance and fat content are not causally related to longevity. It should be stressed that viability selection is probably effective only within certain physiological limits. If environmental stress during the developmental stages has become too severe, viability will drop to very low values. The surviving individuals, however, will most likely not show an increase in adult longevity because of a breakdown of homeostasis resulting from abnormal development. Indeed it has been shown that very low viability is accompanied by low longevity (Economos \& Lints, 1984b, 1986). It also should be noted that not all adult fitness characters will necessarily be increased by viability selection. For instance, it is well known that female flies grown under crowded conditions have a lower total lifetime fecundity than uncrowded females (Lints \& Lints, 1969; Prout \& McChesney, 1985), probably because of their smaller body size. However, recently Quitana \& Prevosti (1990) have shown that resistance to high temperature in D. subobscura was improved for adults grown under larval crowding, which indicates that improvement due to larval crowding applies to many adult fitness traits.

2 During the pre-adult stage a change in adult physiology is induced, resulting in increased fat content. This may be caused by a change in food quality and availability when the larvae develop and alter the medium, or may be caused by differences in adult gene regulation through gene-environment interaction. As a consequence of these changes longevity is increased. This increase could be the direct consequence of an increased fat content. In ageing individuals many normal body functions, such as food intake, are impaired and, consequently, relative fat content will determine the total duration of adult life, because it principally determines survival time without food (David et al., 1975a,b; this study). Starvation during the senescent period need not necessarily exhaust all fat. It is possible that only maintenance fat reserves are used. This may explain the different results for females and males (Fig. 4) because there is evidence that males use more (64 per cent) of their total fat for maintenance than females (19 per cent) (Geer et al., 1970). Little is known about the precise physiological changes during ageing and the exact causes of death in Drosophila, yet this type of information is crucial for the above mentioned hypothesis. Therefore, further experimental research into the relationship between starvation and longevity is needed to test the validity of our hypothesis.

Selection for longevity in Drosophila, through the age at reproduction, has been shown to be successful only when uncontrolled high larval densities were used 
(Rose, 1984; Luckinbill \& Clare, 1985). The selected long-living phenotype is only expressed at higher larval densities, and it has been suggested that the physiological mechanism for this density-threshold is rooted in the complex of physical effects and feeding relationships that develop as burrowing larvae alter the medium and mature (Luckinbill \& Clare, 1986). It has been suggested that this gene-environment interaction during the larval period is responsible for programming the eventual beginning of the senescent period (Arking, 1987). It is possible that the density-threshold for the expression of longevity in selected lines could be the result of an increased fat content in high density groups, as in our experiments. This may imply that either there is no onset-programming of adult senescence at the larval stage, or that the programming of senescence is reflected in a change in adult physiology, and especially in a change in fat content and starvation resistance in the adult stage. It is thus interesting to note that in lines of $D$. melanogaster selected for postponed senescence (Rose, 1984), both starvation resistance (Service et al., 1985) and fat content (Service, 1987) were increased.

In conclusion it can be stated that pre-adult developmental time and growth rate do not explain the observed variation in longevity found in our experiments. Our data, however, make it plausible that changed adult physiology and/or viability selection can explain the observed differences in adult longevity and starvation resistance (fat content).

\section{Acknowledgements}

These investigations were supported by the Foundation for Biological Research (BION), which is subsidized by the Netherlands Organization for Scientific Research (NWO; grant no. 811-436-106). We would like to thank Professor W. van Delden for critically reading the manuscript and $\mathrm{H}$. Mulder for drawing the figures. We are also grateful to Jetty Sismanoglu for preparing the standard medium and to Laurence Hoeksema-du Pui for assistance with the special media.

\section{References}

ARKING, R. 1987. Successful selection for increased longevity in Drosophila: analysis of the survival data and presentation of a hypothesis on the genetic regulation of longevity. Exp. Geront., 22, 199-220.

BAKKER, K. 1961. An analysis of factors which determine success in competition for food among larvae of Drosophila melanogaster. Arch. Neerl. Zool., 14, 200-281.

BARKER, J. S. F. AND PODGER, R. N. 1970. Interspecific competition between Drosophila melanogaster and Drosophila simulans: effects of larval density on viability, develop- mental period and adult body weight. Ecology, 51, 170-189.

Boulétreau-MERle, J. 1988. Biological factors. In: Lints, F. A. and Soliman, M. H. (eds) Drosophila as a Model Organism for Ageing Studies, Blackie, London, pp. 85-96.

DAVID, J. R., COHET, Y. AND FOUILLET, P. 1971. Ralentissement de la croissance et Iongévité des drosophiles adultes: influence d'une sous alimentation larvaire. C. R. Soc. Biol., 165, 2110-2112.

DAVID, J. R., COHET, Y. AND FOUILlET, P. 1975a. Physiologie de l'inanition et utilisation des réserves chez les adultes de Drosophila melanogaster. Arch. Zool. Exp., 116, 579-590.

DAVID, J. R., COHET, Y. AND FOUILLET, P. 1975b. La résistance à I'inanition chez les insectes: importance de la quantité des réserves lipidiques chez les adultes de Drosophila melanogaster. C. R. Acad. Sci. Paris, 280, 2571-2574.

DAVID, J. R., ALlEMAND, R., VAN HERREWEGE, J. AND COHET, Y. 1983. Ecophysiology:abiotic factors. In: Ashburner, M., Carson, H. L. and Thompson, J. N. (eds) The Genetics and Biology of Drosophila, vol. 3d, Academic Press, London, pp. 105-170.

ECONOMOS, A. C. AND LinTs, F. A. 1984a. Growth rate and lifespan in Drosophila. I. Methods and mechanisms of variation of growth rate. Mech. Age. Dev., 27, 1-13.

ECONOMOS, A. C. AND LinTS, F. A. 1984b. Growth rate and lifespan in Drosophila. II. A biphasic relationship between growth rate and life-span. Mech. Age. Dev., 27, 143-151.

ECONOMOS, A. C. AND LINTS, F. A. 1986. Developmental temperature and life-span in Drosophila melanogaster. I. Constant developmental temperature: evidence for physiological adaptation in a wide temperature range. Gerontology, 32, 18-27.

FAIRBANKS, L. D. AND BURCH, G. E. 1970. Rate of water loss and water and fat content of adult Drosophila melanogaster of different ages. J. Insect Physiol, 16, 1429-1436.

FAIRBANKS, L. D. AND BURCH, G. E. 1974. Changes with age in the ability of adult Drosophila melanogaster to respond to yeast feeding. Physiol. Zool., 47, 190-197.

Finney, D. J. 1947. Probit Analysis. Cambridge Academic Press, Cambridge.

GEER, B. W., OLANDER, R. M. AND SHARP, P. L. 1970. Quantification of dietary choline utilization in adult Drosophila melanogaster by radioisotope methods. I. Insect Physiol., 16, 33-43.

KIRKLAND, J. L. 1989. Evolution and ageing. Genome, 31, 398-405.

LINTS, F. A. 1978. Genetics and Ageing. Interdisciplinary Topics in Gerontology, Karger, Basel.

LINTS, F. A. 1985. Insects. In: Finch, C. E. and Schneider, E. L. (eds) Handbook of the Biology of Ageing, Van Nostrand Reinhold Company, New York, pp. 146-169.

LINTS, F. A. 1988. Genetics. In: Lints, F. A. and Soliman, M. H. (eds) Drosophila as a Model Organism for Ageing Studies, Blackie, London, pp. 99-118.

LINTS, F. A. AND LINTS, C. v. 1969. Influence of preimaginal environment on fecundity and ageing in Drosophila melanogaster hybrids. I. Preimaginal population density. Exp. Geront., 4, 231-244. 
LINTS, F. A. AND LINTS, C. v. 1971a. Influence of preimaginal environment on fecundity and ageing in Drosophila melanogaster hybrids. III. Developmental speed and lifespan. Exp. Geront., 6, 427-445.

LINTS, F. A. AND LINTs, c. v. 1971b. Relationship between growth and ageing in Drosophila. Nature New Biol., 229, 86-87.

LUCKINBILL, L. A. AND CLARE, M. J. 1985. Selection for life-span in Drosophila melanogaster. Heredity, 55, 9-18.

LUCKINBILL, L. S. AND ClARE, M. J. 1986. A density threshold for the expression of longevity in Drosophila melanogaster. Heredity, 56, 329-335.

MAYER, P. J. AND BAKER, G. T. 1985. Genetic aspects of Drosophila as a model system of eukaryotic aging. Int. Rev. Cytol., 95, 61-102.

medawar, P. B. 1952. An Unsolved Problem of Biology. H. K. Lewis, London.

MILLER, R. S. AND THOMAS, J. L. 1958. The effects of larval crowding and body size on the longevity of adult Drosophila melanogaster. Ecology, 39, 118-125.

MULLER, H. J. 1963. Mechanisms of life-span shortening. In: Harris, R. J. C. (ed) Cellular Basis and Aetiology of Late Somatic Effects of Ionizing Radiation, Academic Press, New York, pp. 235-245.

PARTRIDGE, L. 1986. Sexual activity and life-span. In: Collatz, K. G. and Sohal, R. S. (eds) Insect Aging, Springer-Verlag, Berlin, pp. 45-54.
PROUT, T. AND MCCHESNey, F. 1985. Competition among immatures affects their adult fertility: population dynamics. Am. Nat., 126, 521-558.

QUiNTANA, A. AND PREvosti, A. 1990. Genetic and environmental factors in the resistance of Drosophila subobscura adults to high temperature shock. I. Breeding temperature and crowding. Theor. Appl. Genet., 79, 103-107.

ROSE, M. R. 1984. Laboratory evolution of postponed senescence in Drosophila melanogaster. Evolution, 38, 1004-1010.

SERVICE, P. M. 1987. Physiological mechanisms of increased stress resistance in Drosophila melanogaster selected for postponed senescence. Physiol. Zool., 60, 321-326.

SERVICE, P. M. 1989. The effect of mating status on life-span, egg laying, and starvation resistance in Drosophila melanogaster in relation to selection on longevity. J. Insect. Physiol., 35, 447-452.

SERVICE, P. M., HUTCHINSON, E. W., MACKINLEY, M. D. AND ROSE, M. R. 1985. Resistance to environmental stress in Drosophila melanogaster selected for postponed senescence. Physiol. Zool., 58, 380-389.

SOKAL, R. R. AND ROHLF, F. J. 1969. Biometry. W. H. Freeman and Company, San Francisco.

Williams, G. C. 1957. Pleiotropy, natural selection and the evolution of senescence. Evolution, 11, 398-411. 